\title{
Social Desirability Bias in Sexual Behavior Reporting: Evidence from an Interview Mode Experiment in Rural Malawi
}

\begin{abstract}
By Christine
A. Kelly, Erica

Soler-Hampejsek, Barbara S. Mensch and Paul C. Hewett
\end{abstract}

Christine A. Kelly is staff associate,

Erica Soler-

Hampejsek is associate and Barbara S. Mensch is senior associate-all with the Population Council, New York. Paul C. Hewett is senior associate, Population Council, Lusaka, Zambia.
CONTEXT: Social desirability bias is problematic in studies that rely on self-reported sexual behavior data. Where gender norms create different expectations about socially acceptable behavior, males and females face distinct pressures in reporting certain outcomes, which can distort assessments of risk for HIV and STIs.

METHODS: In 2009, relationship and sexual behavior data were collected from 1,750 never-married males and females aged 16-18 via audio computer-assisted self-interviewing (audio-CASI) during the third round of the Malawi Schooling and Adolescent Study. A comparison group of 311 youth completed an identical questionnaire in face-to-face interviews. To assess whether interview mode may have influenced participants'reporting of sensitive behavior, reports of sexual experience in the two groups were compared. Multiple logistic regression analysis was used to identify associations between interview mode and reports of these behaviors, by gender.

RESULTS: In adjusted regression models, males were less likely to report ever having had a girlfriend in audio-CASI than in face-to-face interviews (odds ratio, 0.4), but they were more likely to report having had sex with a relative or teacher (3.5). For females, reports of ever having had a boyfriend or having had sex did not differ between modes. A small proportion of females reported ever having had sex with a relative or teacher in audio-CASI, while none did so in face-to-face interviews.

CONCLUSIONS: The method used for collecting relationship and sexual behavior data may influence the reported prevalence of some key behaviors, particularly among males. Further research is needed to improve methods of collecting sensitive data.

International Perspectives on Sexual and Reproductive Health, 2013, 39(1):14-21, doi: 10.1363/3901413
Collection of accurate behavioral data is critical for understanding the transmission dynamics of HIV and other STIs and for designing and evaluating interventions aimed at containing their spread. Researchers usually rely on selfreported data, which are subject to participants' recall bias, question misinterpretation and reluctance to respond truthfully when asked about private behavior. ${ }^{1}$ Social desirability bias is particularly problematic in studies involving sexual behavior, as respondents may deliberately answer questions inaccurately, either by underreporting stigmatized activities or by overreporting normative ones, if their actual behavior would be considered socially unacceptable. $^{2}$

Potential respondent biases may be reduced or exacerbated by the method of questionnaire delivery. Surveys administered via face-to-face interviews, for instance, can be influenced by interviewers' inaccurate rewording of questions, directive probes, nonverbal cues or inappropriate feedback. ${ }^{3}$ Real or perceived judgment on the part of the interviewer, or concerns participants have about the privacy of their responses, may prevent them from providing honest answers to sensitive questions.

Although the bulk of survey data from developing countries-including Demographic and Health Survey (DHS) data sets-is traditionally collected in face-to-face interviews, increasing use has been made of technologybased alternatives, such as audio computer-assisted selfinterviewing (audio-CASI). ${ }^{4}$ With this method, participants listen to questions through headphones and enter responses using an electronic device, such as a laptop or handheld computer. This technique provides greater standardization than other interview methods by administering an identical script to each respondent and by eliminating interviewer effects. Audio-CASI also affords greater privacy to participants than other modes, and thus has the potential to reduce social desirability bias in the reporting of sensitive or stigmatized behaviors.

Use of audio-CASI has been shown to be feasible in low-resource settings (e.g., Kenya, ${ }^{5}$ Malawi, ${ }^{6}$ Zimbabwe, ${ }^{7}$ Brazil, ${ }^{8}$ India ${ }^{9}$ and Vietnam ${ }^{10}$ ) and has led to higher reporting of some outcomes. However, these and other studies have shown that results may vary by setting and sample. A systematic review of questionnaire delivery modes in developing countries found that, overall, respondents were less likely to report sensitive behaviors in face-to-face interviews than in audio-CASI, ${ }^{11}$ while a second review and meta-analysis of quantitative interviewing tools in low- and middle-income countries concluded that results depended on the sensitivity of the outcome and the population under study. ${ }^{4}$ 
Motivations to report behavior truthfully may also vary by gender, particularly regarding sexual activity in contexts where gender norms create different expectations for males and females about socially acceptable behavior. ${ }^{12}$ In Malawi, as in much of Sub-Saharan Africa, premarital and extramarital sex are considered symbols of masculine prowess, ${ }^{13}$ but for females, sexual activity outside of marriage is discouraged, and the social costs of reporting it are higher. ${ }^{14}$

In a study that compared reporting by males and females via face-to-face interviews at a demographic surveillance site in Malawi's Karonga district, significant gender differences were found in the reporting of sexual partnerships, demonstrating that some combination of male overreporting and female underreporting occurred. ${ }^{15}$ Results from an earlier study at a Tanzanian demographic surveillance site were similar. ${ }^{16}$ Men have also been found to consistently report higher levels of premarital sex and risky sexual activity than have women in the DHS and other surveys. ${ }^{17,18}$

To determine whether interview mode influences levels of reporting for each gender, the present study compares responses to sexual behavior questions administered via audio-CASI with those obtained via traditional face-to-face interviews. Given the social norms surrounding relationships and sex in rural Malawi, we expected to observe different patterns of reporting between interview modes for males and females. Specifically, we hypothesized that males' reporting of relationship experience and sexual activity would be higher in face-to-face interviews than in audio-CASI, and that the opposite would be the case for females. ${ }^{10,19,20}$ However, for socially proscribed behaviors, we expected reporting to be higher in audio-CASI for both genders.

\section{METHODS}

\section{Study Design and Samples}

The audio-CASI method featured in this analysis is used in the Malawi Schooling and Adolescent Study (MSAS), a longitudinal survey administered yearly since 2007. The baseline sample comprised 2,650 adolescents-1,312 males and 1,338 females-aged 14-16 in January of that year. Two-thirds of the adolescents ( 889 males and $875 \mathrm{fe}$ males) were students attending standards (grades) 4-8 at recruitment and were randomly selected from enrollment rosters at 59 primary schools in Balaka and Machinga, two contiguous rural districts in the southern region of the country.* The probability of a particular school being selected was proportional to its enrollment in 2006. Approximately 30 students stratified by gender and age were selected from each school. The remaining third of participants (423 males and 463 females) were not attending school when first interviewed in 2007. ${ }^{\dagger}$ These adolescents, who lived in the catchment villages of the participating schools, were identified through key informants at each study school or in randomly selected communities in each school's catchment villages. Follow-up interviews have been conducted annually through 2011, and approximately $90 \%$ of adolescents in the original sample have been re- interviewed each year.

The audio-CASI data used here come from the third round of the MSAS, conducted in May through July 2009, during which 1,165 males and 1,219 females were interviewed. For the majority of respondents (94\%), this was the third time they had been exposed both to the use of audio-CASI and to the series of sexual behavior questions featured in this study.

A supplementary random sample of adolescents was selected in 2009 to serve as a comparison group for this methodological experiment. A household census conducted in catchment villages of the MSAS schools provided the sampling frame. Twelve of the 59 study schools were randomly selected, with a probability of inclusion proportional to enrollment in 2006. For each selected school, four catchment villages were randomly chosen, with the exception of one school with particularly large catchment villages, for which two villages were selected. Each household in the selected villages was approached for participation in the census, during which basic social and demographic information about the household and its members was collected. ${ }^{\dagger}$ From the household rosters, adolescents aged 16-18 at the start of 2009 were identified and followed up for interview. This age-group was chosen to make the sample directly comparable to the MSAS participants. In total, 407 eligible adolescents (200 males and 207 females) completed the interview, representing a completion rate of nearly $80 \%$.

As a longitudinal study, the MSAS is subject to attrition across rounds, such that the subset of the baseline sample interviewed in 2009 does not necessarily share the characteristics of a purely random sample. ${ }^{\S}$ In addition, as noted earlier, the baseline MSAS sample was constructed according to schooling status, and for current students it was restricted to those attending standards 4-8. Since the supplementary sample did not share this design, we might expect some background characteristics to vary between the two groups.

The MSAS instrument consists of an extensive set of questions on household and family characteristics, schooling and employment history, marriage and childbirth, health and sexual behavior, as well as literacy and numeracy assessments. Participants in our study completed the questionnaire using a combination of interview modes. For the MSAS group, nonsensitive questions were administered via face-to-face interviews, and sensitive questions related to puberty, sexual behavior, physical abuse, and drug and alcohol use were asked using audio-CASI. The entire MSAS questionnaire was administered to the

*The original sample included 60 primary schools, but one school in Balaka could not be reached in 2007 because a bridge had washed away during the rainy season. The 29 schools sampled in Balaka represented nearly $25 \%$ of the schools in the district, and the 30 in Machinga represented nearly $20 \%$ of that district's schools.

tThe ratio of adolescents in standards 4-8 relative to those out of school approximates that observed in the 2004 Malawi DHS.

‡ln one very large village, every 10th household was sampled.

§In addition, MSAS literacy and numeracy scores may be influenced by repeated exposure to the evaluation exercise. 
supplementary sample via face-to-face interviews. A local team of trained interviewers, matched to participants by gender, administered the survey to the MSAS sample; a subset of these interviewers were selected to conduct the face-to-face interviews with the participants in the supplementary sample. All interviews were offered in Chichewa and Chiyao; nearly all participants (98\%) chose Chichewa, Malawi's national language.

Written informed consent was obtained from all participants. For individuals in the MSAS sample who were enrolled in school, teachers were provided a letter to read to standards 4-8 and students were asked to inform their parents of potential participation in the study. Participants were asked to confirm their parents' approval as part of the informed consent process. For out-of-school participants in the MSAS sample, and for all individuals in the supplementary sample, consent was first obtained from participants' parents or guardians, and then from the participants themselves. Interviews for both the MSAS and the supplementary sample were conducted at school, the household or a public place, according to where participants could be located. The research protocol was approved by the Population Council institutional review board in New York and the University of Malawi Research and Publications Committee in Zomba.

The present analysis, which focuses on premarital sexual behavior, includes 1,104 males and 646 females in the MSAS (audio-CASI) sample and 195 males and 116 females in the supplementary (face-to-face interview) sample who had never been married and for whom all relevant data were available.*

\section{Outcome Variables}

To assess differences in the reporting of relationships and sexual behavior according to mode of interview, we focused on three outcomes.

- Ever had a boyfriend or girlfriend. Participants were asked if they had ever had a chibwenzi, which in Chichewa signifies "boyfriend" or "girlfriend."

- Ever had sex. After defining sex as "full penetration" and making clear that episodes of forced sex should be included, respondents were asked to report sexual activity in two ways. First, they were asked their age at sexual debut, with the option of answering "never had sex." Next, all respondents-including those who had not reported an age at first sex-were asked a sequence of questions about whether they had ever had sex with specific types of partners, including a boyfriend or girlfriend, a "hit and run" (a person with whom the respondent had had a single sexual encounter), a relative, a teacher or any other partner. Although both audio-CASI and face-to-face interviews lend themselves to the inclusion of skip patterns, and such patterns were used in other sections of the survey, we decided to ask the series of partner questions to all respondents, regardless of whether they had provided an age at first sex. This decision reflected previous research by the authors in Kenya ${ }^{5}$ and Malawi ${ }^{6}$ that had demonstrated that some adolescents who did not initially report having had sex subsequently acknowledged sexual activity when further probed about specific partners. Interviewers reconciled inconsistent responses to the sexual behavior components, but in the audio-CASI interview, it was possible to report an age at first sex but no partner, and vice versa. We therefore considered an adolescent to have ever had sex if he or she answered affirmatively to any one of the questions on age at first sex or partner.

- Ever had sex with a stigmatized partner. We define a stigmatized partner as a relative or a teacher, owing to the particular disapprobation associated with these relationships for adolescents. We determined whether an adolescent had had sex with such a partner from responses to the series of partner questions.

For purposes of comparison between the interview groups, we also assessed two measures unrelated to relationships and sex: whether a respondent had drunk alcohol or stolen from a kiosk or vendor. ${ }^{\ddagger}$ For students, these questions referred to the past school year (which began the preceding January); for those not enrolled, questions referred to the period since January 1, 2009.

\section{Independent Variables}

Participants provided information on a number of social and demographic characteristics: age, ethnic group, religion, coresidence with parents and household assets. ${ }^{\S}$ They also answered questions about current school status and highest grade ever attended, and completed exercises measuring their literacy and numeracy skills. Respondents were considered literate if they could successfully read two simple sentences in Chichewa, taken from the 2004 Malawi DHS.
*The differences in the male and female sample sizes are attributable to the greater likelihood of females in this age-group being married and therefore excluded from analysis. Of the 1,165 males who completed round 3 of the MSAS, 53 had ever been married and data were missing for eight; of the 1,219 sampled females, 566 had ever been married and data were missing for seven. In the supplementary sample, four males had ever been married and data were missing for one; 91 females had ever been married, but data were complete for the remaining 116.

†Although in Malawi having a chibwenzi is typically equated with having sex (source: Poulin M, Sex, money, and premarital partnerships in southern Malawi, Social Science \& Medicine, 2007, 65(11):2383-2393), a minority of Malawian youth have been shown to report nonsexual romantic relationships in both qualitative (source: Munthali AC et al., Qualitative evidence of adolescents' sexual and reproductive health experiences in selected districts of Malawi, Occasional Report, New York: Guttmacher Institute, 2006, No. 23) and quantitative (source: Bankole A et al., Sexual be- havior, knowledge and information sources of very young adolescents in four Sub-Saharan African countries, African Journal of Reproductive Health, 2007, 11(3):28-43) studies.

$\neq$ According to a national survey, $17 \%$ of females and $24 \%$ of males aged 15-19 had ever drunk alcohol, of whom $27 \%$ and $52 \%$, respectively, reported getting drunk in the past year (source: Munthali $A$ et al., Adolescent sexual and reproductive health in Malawi: results from the $2004 \mathrm{Na}$ tional Survey of Adolescents, Occasional Report, New York: Guttmacher Institute, 2006, No. 24).

§Respondents were asked if their household had any of the following goods or services: mattress, sofa, table, chairs, paraffin gas lamp, television, radio, cell phone, mosquito net, bicycle, motorcycle, car, tin roof electricity, boat or canoe, or books to read. A count of assets was included as a continuous variable in regression models; results did not change in any significant way when we substituted an asset index generated by using principal component analysis. 
TABLE 1. Selected social and demographic characteristics of never-married individuals in the Malawi Schooling and Adolescent Study (MSAS) sample and the supplementary random sample (SRS) of an interview mode experiment, by gender, Malawi, 2009

Characteristic

\begin{tabular}{ll|ll} 
Male & & \multicolumn{2}{|l}{ Female } \\
\hline SRS & MSAS & SRS & MSAS \\
$(\mathrm{N}=195)$ & $(\mathrm{N}=1,104)$ & $(\mathrm{N}=116)$ & $(\mathrm{N}=646)$
\end{tabular}

\begin{tabular}{lrl|rc}
\hline Individual & & & & \\
Mean age & 17.1 & $17.2^{*}$ & 16.9 & $17.1 \dagger$ \\
Currently in school & 70.3 & $61.1^{*}$ & 76.7 & 70.9 \\
Mean highest grade & & & & \\
$\quad$ attended & 7.0 & 6.9 & 7.5 & 7.8 \\
Literate in Chichewa & 81.0 & 82.7 & 81.9 & $90.6^{* *}$ \\
Mean numeracy score§ & 8.1 & 8.2 & 7.9 & $8.8^{* *}$ \\
Tribe & & & & \\
$\quad$ Yao & 39.5 & 40.9 & 38.8 & 34.7 \\
$\quad$ Chewa & 13.8 & $19.8^{*}$ & 24.1 & 20.3 \\
$\quad$ Lomwe & 21.5 & 21.6 & 19.0 & 24.3 \\
$\quad$ Other & 25.1 & $17.6^{*}$ & 18.1 & 20.7 \\
Religion & & & & \\
$\quad$ Muslim & 43.6 & 43.2 & 37.1 & 37.3 \\
$\quad$ Other & 56.4 & 56.8 & 62.9 & 62.7 \\
& & & & \\
Household & & & & \\
Mean no. of assetst† & 5.7 & 5.5 & 5.4 & $6.0 \dagger$ \\
Resides with mother & & & & \\
$\quad$ Yes & 65.6 & 66.7 & 67.2 & 66.4 \\
$\quad$ No, mother alive & 15.9 & 16.6 & 14.7 & 17.5 \\
$\quad$ No, mother dead & 18.5 & 16.8 & 18.1 & 16.1 \\
Resides with father & & & & \\
$\quad$ Yes & 41.5 & 37.5 & 44.0 & 42.9 \\
$\quad$ No,father alive & 34.4 & 31.3 & 33.6 & 28.0 \\
$\quad$ No,father dead & 24.1 & $31.2^{*}$ & 22.4 & 29.1 \\
\hline
\end{tabular}

${ }^{*} p<.05 .{ }^{* *} p<.01 .+p<.10$. $\neq$ Based on successfully reading two simple sentences in Chichewa, taken from the 2004 Malawi DHS. §The sum of correct answers in a 12-question exercise involving ordering numbers; performing addition, subtraction, multiplication and division; and solving simple word problems. Questions were drawn from the Malawi Institute of Education achievement test for primary school standard 3. t+From a list of 16 goods and services: mattress, sofa, table, chairs, paraffin gas lamp, television, radio, cell phone, mosquito net, bicycle, motorcycle, car, tin roof, electricity, boat or canoe, and books to read. Notes: Figures are percentages unless noted otherwise. Percentage distributions may not total 100.0 because of rounding.

A numeracy score was generated by summing the number of correct answers in a 12-question exercise that involved ordering numbers; performing addition, subtraction, multiplication and division; and solving simple word problems, all of which were drawn from the Malawi Institute of Education achievement tests for primary school standard 3.

\section{Analysis}

We used two-sided $z$ tests for proportions and tests for means to compare the social and demographic characteristics of the two samples, separately for males and females. We also compared reports of each relationship, sexual, alcohol and theft outcome across interview modes. We then estimated multiple logistic regression models by gender to identify associations between interview mode and reporting of ever having had a boyfriend or girlfriend, ever having had sex and ever having had sex with a stigmatized partner. Standard errors were adjusted for clustering within interviewer.

All regression models controlled for variables related to educational attainment and skills, both because of the known link between school attendance and sexual activity $^{21}$ and as a proxy for the respondent's ability to understand and respond to survey questions. The models also included the other social and demographic characteristics presented in Table 1, as these could influence adolescents' reporting of sexual behavior, ${ }^{22}$ and serve to control for observed differences between the two samples. In addition, to test whether multiple exposures to the MSAS questionnaire may have affected responses in the audio-CASI group, we compared the reporting of participants with complete data who were aged 16 at the start of 2007-when they were first exposed to the audio-CASI instrument-with that of individuals in the supplementary sample who were 16 at the start of 2009. These groups would be expected to have comparable levels of premarital sexual experience. Finally, the internal consistency of reporting sensitive behavior using audio-CASI was assessed. Analysis was conducted using Stata version 12.1.

\section{RESULTS}

\section{Sample Characteristics}

Overall, participants had a mean age of 17 (Table 1). The majority were currently attending school and were literate in Chichewa. Approximately 40\% were Muslim, corresponding with the proportion belonging to the Yao tribe; the remainder were predominantly Christian, and members of the Chewa, Lomwe and other tribes. Two-thirds of participants resided with their mother, and almost a fifth reported that their mother had died; about one-quarter of participants had lost their father.

For both genders, significant differences in social and

\begin{tabular}{|c|c|c|c|c|}
\hline \multirow[t]{2}{*}{ Experience } & \multicolumn{2}{|l|}{ Male } & \multicolumn{2}{|l|}{ Female } \\
\hline & $\begin{array}{l}\text { FTFI } \\
(\mathrm{N}=195)\end{array}$ & $\begin{array}{l}\text { Audio-CASI } \\
(\mathrm{N}=1,104)\end{array}$ & $\begin{array}{l}\text { FTFI } \\
(\mathrm{N}=116)\end{array}$ & $\begin{array}{l}\text { Audio-CASI } \\
(\mathrm{N}=646)\end{array}$ \\
\hline Ever had boyfriend/girlfriend & 69.2 & $48.9^{* * *}$ & 44.0 & 38.2 \\
\hline \multicolumn{5}{|l|}{ Age at first sex } \\
\hline Age reported & 70.3 & $54.7^{* * *}$ & 39.7 & 37.2 \\
\hline Mean age at first sex & 13.7 & 13.7 & 15.1 & 14.8 \\
\hline \multicolumn{5}{|l|}{ Partner type } \\
\hline Boyfriend/girlfriend & 62.6 & $40.2^{* * *}$ & 35.3 & 31.3 \\
\hline Hit and run & 20.5 & $12.8^{* *}$ & 2.6 & 4.2 \\
\hline Relative & 3.1 & $8.2^{*}$ & 0.0 & $3.7^{*}$ \\
\hline Teacher & 0.0 & $2.6^{*}$ & 0.0 & 1.7 \\
\hline Other & 7.7 & $12.3 \dagger$ & 1.7 & 4.5 \\
\hline Any partner & 70.3 & $51.6^{* * *}$ & 39.7 & 35.6 \\
\hline Any stigmatized partner & 3.1 & $10.0^{* *}$ & 0.0 & $4.8^{*}$ \\
\hline Had had sex‡ & 70.3 & $62.1^{*}$ & 39.7 & 44.9 \\
\hline \multicolumn{5}{|l|}{ Other } \\
\hline Alcohol use§ & 6.2 & 3.7 & 0.9 & 3.3 \\
\hline Petty theft+† & 6.7 & 5.4 & 3.4 & 5.9 \\
\hline
\end{tabular}

${ }^{*} \mathrm{p}<.05 .{ }^{* *} \mathrm{p}<.01 .{ }^{* * *} \mathrm{p}<.001 .+\mathrm{p}<.10 . \neq$ Aggregate measure based on respondent reporting an age at first sex or having had sex with a particular partner type, or both. §Respondents attending school at the time of interview were asked if they had drunk alcohol in the past school year; those not in school were asked about use since January 1, 2009. t+Respondents were asked if they had stolen something from a kiosk or vendor; the time frames were the same as for the alcohol use measure. Notes: Figures are percentages unless noted otherwise. FTFI= face-to-face interview. Audio-CASI= audio computer-assisted self-interviewing. 
TABLE 3. Odds ratios (and 95\% confidence intervals) from multiple logistic regression analysis identifying associations between reports of relationship, sexual and other experience and use of audio-CASI rather than face-to-face interviews, by gender

\begin{tabular}{|c|c|c|c|c|}
\hline \multirow[t]{2}{*}{ Experience } & \multicolumn{2}{|l|}{ Male $(\mathrm{N}=1,299)$} & \multicolumn{2}{|l|}{ Female $(\mathrm{N}=762)$} \\
\hline & Unadjusted & Adjusted & Unadjusted & Adjusted \\
\hline \multicolumn{5}{|l|}{ Relationship/sex } \\
\hline Ever had boyfriend/girlfriend & $0.43(0.29-0.61)^{* * *}$ & $0.40(0.27-0.57)^{* * *}$ & $0.79(0.53-1.18)$ & $0.71(0.49-1.02)$ \\
\hline Ever had sex‡ & $0.69(0.43-1.10)$ & $0.66(0.42-1.04) \dagger$ & $1.24(0.88-1.75)$ & $1.13(0.79-1.61)$ \\
\hline Ever had sex with relative/teacher & $3.49(1.95-6.22)^{* * *}$ & $3.49(2.01-6.05)^{* * *}$ & na§ & na§ \\
\hline \multicolumn{5}{|l|}{ Other } \\
\hline Alcohol uset† & $0.59(0.27-1.27)$ & $0.61(0.28-1.35)$ & $3.86(0.54-27.64)$ & $3.14(0.32-30.83)$ \\
\hline 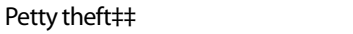 & $0.80(0.43-1.50)$ & $0.85(0.46-1.56)$ & $1.75(0.63-4.90)$ & $1.82(0.61-5.46)$ \\
\hline
\end{tabular}

${ }^{*} \mathrm{p}<.05 .{ }^{* *} \mathrm{p}<.01 .{ }^{* * * *} \mathrm{p}<.001 .+\mathrm{p}<.10$. Agggregate measure based on respondent reporting an age at first sex or having had sex with a particular partner type or both. §Since no females reported sex with a relative or teacher in face-to-face interviews, interview mode perfectly predicts reporting of this outcome. t+Respondents attending school at the time of interview were asked if they had drunk alcohol in the past school year; those not in school were asked about use since January 1,2009. ¥¥Respondents were asked if they had stolen something from a kiosk or vendor; the time frames were the same as for the alcohol use measure. Notes: Adjusted models control for the social and demographic characteristics shown in Table 1. na=not applicable.

demographic characteristics were found between the supplementary and MSAS samples, but given the differences in sampling design, these were relatively modest. MSAS males were slightly older than their counterparts in the supplementary sample, but a higher proportion of the latter group were attending school. Among females, a larger proportion in the MSAS sample than in the supplementary sample were proficient in Chichewa and math. Regarding household characteristics, a slightly higher proportion of MSAS males reported that their father had died.

\section{Relationship and Sexual Behavior Outcomes}

A greater proportion of males than of females reported having had sex, irrespective of questionnaire delivery mode (not shown). However, differences in reporting between face-to-face interviews and audio-CASI for both genders were also observed.

Overall, the proportion of males participating in face-toface interviews who reported ever having a girlfriend was significantly greater than that of males who used audioCASI (69\% vs. 49\%-Table 2, page 17). The difference was smaller among females (44\% vs. 38\%) and not significant. A greater proportion of males reported their age at first sex in face-to-face interviews than in audio-CASI (70\% vs. $55 \%$ ), while for females the difference was smaller (40\% vs. 37\%) and not significant. For those who reported an age at first sex, there was no difference in the mean age of initiation across modes of interview for either gender

Although greater proportions of males acknowledged having had sex with a girlfriend (63\% vs. 40\%), a "hit and run" ( $21 \%$ vs. $13 \%)$ or any partner ( $70 \%$ vs. $52 \%$ ) in faceto-face interviews than in audio-CASI, the level of reporting was not universally higher in the former group for each partner type. Notably, greater percentages of males who used audio-CASI reported having had sex with a relative $(8.2 \%$ vs. $3.1 \%)$ or a teacher $(2.6 \%$ vs. $0.0 \%)$. Females in the audio-CASI group were also more likely than their counterparts to report having had sex with a relative $(3.7 \%$ vs. $0.0 \%$ ). When responses to the age at first sex and partner questions were used in combination to determine sexual experience, $70 \%$ of males reported premarital sex in face-to-face interviews, compared with $62 \%$ in audio-CASI. The opposite pattern was observed for females, but the difference was not significant. Reporting of alcohol use and petty theft was universally low and not significantly different across interview modes for either gender.

\begin{tabular}{|c|c|c|c|c|}
\hline \multirow[t]{2}{*}{ Experience } & \multicolumn{2}{|l|}{ Male $(\mathrm{N}=422)$} & \multicolumn{2}{|l|}{ Female $(\mathrm{N}=293)$} \\
\hline & Unadjusted & Adjusted & Unadjusted & Adjusted \\
\hline \multicolumn{5}{|l|}{ Relationship/sex } \\
\hline Ever had boyfriend/girlfriend & $0.44(0.26-0.75)^{* *}$ & $0.45(0.25-0.80)^{* *}$ & $0.69(0.36-1.32)$ & $0.69(0.34-1.38)$ \\
\hline Ever had sex $\neq$ & $1.13(0.66-1.92)$ & $1.16(0.68-1.98)$ & $2.15(1.14-4.07)^{*}$ & $1.84(1.08-3.14)^{*}$ \\
\hline Ever had sex with relative/teacher & $3.16(1.01-9.23)^{*}$ & $2.95(0.98-8.84) \dagger$ & na§ & na§ \\
\hline \multicolumn{5}{|l|}{ Other } \\
\hline Alcohol uset† & $0.75(0.25-2.27)$ & $0.75(0.24-2.38)$ & na§ & na§ \\
\hline Petty theft㧊 & $0.51(0.16-1.62)$ & $0.54(0.18-1.62)$ & $0.38(0.06-2.23)$ & $0.21(0.04-1.07) \dagger$ \\
\hline
\end{tabular}

${ }^{*} \mathrm{p}<.05 .{ }^{* *} \mathrm{p}<01{ }^{* * * *} \mathrm{p}<0.01 . \mathrm{t}<<10$. $\neq$ Aggregate measure based on respondent reporting an age at first sex or having had sex with a particular partner type, or both. §Since no females reported sex with a relative or teacher or alcohol use in face-to-face interviews, interview mode perfectly predicts reporting of these outcomes. ††Respondents attending school at the time of interview were asked if they had drunk alcohol in the past school year; those not in school were asked about use since January 1,2009. ¥¥Respondents were asked if they had stolen something from a kiosk or vendor; the time frames were the same as for the alcohol use measure. Notes: Adjusted models control for the social and demographic characteristics shown in Table 1, with the exception of age. na=not applicable. 
The multiple logistic regression results for each outcome largely corroborate the findings from Table 2. In adjusted models, males in the audio-CASI group were significantly less likely than those in the face-to-face interview group to report ever having had a girlfriend (odds ratio, 0.4-Table 3), but not to have ever had sex. Neither outcome varied significantly by interview mode for females. The finding that males in the audio-CASI group were more likely than those in the other group to report ever having had sex with a stigmatized partner was highly significant (3.5). Since no females reported sex with a relative or teacher in face-toface interviews, interview mode perfectly predicted reporting of this outcome.

\section{Robustness Findings}

In multivariate analysis that compared reporting from 348 males and 245 females when they were 16 and first exposed to the audio-CASI instrument in 2007 with reporting from 74 males and 48 females in the supplementary sample who were 16 at the start of 2009, males were less likely to report ever having had a girlfriend in audio-CASI than in face-to-face interviews (odds ratio, 0.5-Table 4), but more likely to report ever having had sex with a relative or a teacher (3.0), although the latter finding was only marginally significant. Females were more likely to report ever having had sex in the computerized interview (1.8).

In an overall assessment of the internal consistency of reporting sexual behavior, among males in the audio-CASI group who said they had had premarital sex, only $71 \%$ reported both an age at first sex and at least one partner; $17 \%$ reported only an age at first sex, and 12\% reported only a sex partner. Among females who used audio-CASI, consistency was lower: Sixty-two percent of those who reported ever having had sex gave both an age and a partner; $21 \%$ gave only an age and $17 \%$ only a partner. We did not observe this problem in the face-to-face interviews, because interviewers were instructed to reconcile discrepant responses to the sexual behavior components.

\section{DISCUSSION}

Our results suggest that the method used for collecting sensitive data may influence the reported prevalence of key behaviors, particularly for males. As expected, nevermarried males were less likely to report having had a girlfriend in audio-CASI than in face-to-face interviews, while sexual encounters with stigmatized partners were reported to a greater degree when using the former method. These results conform with similar reporting patterns in other interview mode experiments involving male samples. ${ }^{19,20}$ Although it is not possible to know respondents' actual behavior in the context of this study, the differences in reporting likely stem from social desirability bias rather than from other sources of error. Males' reporting of other behaviors, including alcohol consumption and petty theft, was not significantly lower in audio-CASI, suggesting that magnified accounts of relationship and sexual experience in face-to-face interviews were not the result of universal overreporting in that mode. Given that males were more likely to report sexual encounters with a relative or teacher in audio-CASI than in face-to-face interviews, it seems improbable that they would underreport more conventional sexual activity when using the computerized method. If we conclude, then, that males exaggerate sexual experience with traditional partners in face-to-face interviews, but underreport their more stigmatized encounters, this has implications for the interpretation of behavioral data collected using this method. These patterns may also help explain the absence of a clear link between self-reported risky behavior and STIs. ${ }^{23,24}$

Contrary to our hypothesis, but reflective of unexpected findings in other studies, ${ }^{6,20}$ females did not report having a boyfriend or premarital sex to a significantly greater degree in audio-CASI than in face-to-face interviews. In a Kenyan study, Luke and colleagues ${ }^{19}$ posit that it is no longer socially unacceptable for young women to engage in monogamous sexual relationships, and therefore we should not expect reporting of traditional sexual partnerships to differ in face-to-face interviews relative to other interview modes. Recent research in Malawi, however, has noted females' continued reluctance to discuss their relationships. ${ }^{14}$ Since we cannot determine actual levels of sexual or relationship experience, we cannot definitively assess the accuracy of reporting in either interview mode, but it is notable that some females acknowledged sexual encounters with a relative or teacher in audio-CASI, whereas none did so in face-to-face interviews. This suggests that audio-CASI was successful in eliciting reports of the most stigmatized behaviors, if not of other outcomes.

It is important to note that the audio-CASI arm of this experiment was drawn from a sample of adolescents who had been interviewed repeatedly as part of the Malawi School and Adolescent Study. Therefore, the 2009 survey data assessed here represent at least the second and often the third occasion that members of the MSAS sample had responded to the same series of sexual behavior questions. Panel conditioning theory suggests that as participants become more comfortable with the researchers and the study instruments through repeated interviews, they may feel less pressure to provide socially desirable responses. ${ }^{25}$ The past experience of MSAS participants with the study, the questionnaire and the use of audio-CASI may therefore have influenced their reporting in ways that would not have affected individuals in the supplementary random sample, who were participating for the first time. Specifically, according to our hypothesis regarding gender differences in divulging sensitive behavior, we might expect reporting of relationships and sexual activity to be lower among MSAS males who had been interviewed three times relative to their baseline reports, and reporting of stigmatized sexual encounters to be higher, all other things being equal. For females, we would expect reporting of all outcomes of interest to increase with the number of interviews.

However, we found that the pattern of reporting among 16-year-old males in their first audio-CASI interview in 
2007 was consistent with that observed for the wider cohort participating for their second or third time in 2009. In contrast, 16-year-old females were more likely to report having had sex in their baseline audio-CASI interview than were their peers who did face-to-face interviews. Hence, the reporting differences observed in this study do not appear to be attributable to panel conditioning.

One limitation of this study is the absence of biomarker data, which provide a more objective means of validating self-reported sexual activity. Identifying STIs among respondents who did not report ever having sex, or measuring the strength of the association between infection and sexual behavior among those who did report it, could shed further light on the accuracy of reporting in each interview mode. ${ }^{16,26,27}$ In addition, some differences in the reporting of age at first sex and sex with specific partners between interview modes could stem from interviewers reconciling discrepant responses to the sexual behavior questions in the face-to-face interviews.

Nevertheless, our results suggest that questionnaire delivery mode influences the reporting of relationships and sexual behavior and that this possible influence differs by gender. On balance, audio-CASI seems to have elicited more moderated reports of overall sexual activity for males, and greater reports of sexual encounters with stigmatized partners for both genders. However, comparison of the two components of the aggregate "ever had sex" indicator reveals that the level of within-round consistency in audioCASI is low, a finding that has been replicated elsewhere. ${ }^{6,20}$

\section{Conclusions}

The self-administered nature of audio-CASI increases the privacy afforded to participants and may therefore reduce the influence of societal expectations on reporting, but it also removes the opportunity for interviewers to probe respondents or clarify questions. Researchers working with self-reported data should continue to develop innovative methods of data collection that attempt to address social desirability bias without compromising other aspects of data quality. ${ }^{14,19}$ Sexual behavior research would also benefit from greater use of biomarker testing as an objective means to validate self-reports. ${ }^{4,28}$

\section{REFERENCES}

1. O'Sullivan LF, Challenging assumptions regarding the validity of self-report measures: the special case of sexual behavior, Journal of Adolescent Health, 2008, 42(3):207-208.

2. Catania JA et al., Methodological problems in AIDS behavioral research: influences on measurement error and participation bias in studies of sexual behavior, Psychological Bulletin, 1990, 108(3):339362.

3. Fowler FJ, Jr., and Mangione TW, Standardized Survey Interviewing: Minimizing Interviewer-Related Error, Newbury Park, CA: Sage Publications, 1990

4. Phillips AE et al., A systematic review and meta-analysis of quantitative interviewing tools to investigate self-reported HIV and STI associated behaviours in low- and middle-income countries, International Journal of Epidemiology, 2010, 39(6):1541-1555.

5. Hewett PC, Mensch BS and Erulkar AS, Consistency in the re- porting of sexual behaviour by adolescent girls in Kenya: a comparison of interviewing methods, Sexually Transmitted Infections, 2004 80(Suppl. 2):ii43-ii48.

6. Mensch BS et al., Sexual behavior and STI/HIV status among adolescents in rural Malawi: an evaluation of the effect of interview mode on reporting, Studies in Family Planning, 2008, 39(4):321-334.

7. Langhaug LF et al., How you ask really matters: randomised comparison of four sexual behaviour questionnaire delivery modes in Zimbabwean youth, Sexually Transmitted Infections, 2011, 87(2):165173

8. Mensch BS et al., Consistency in women's reports of sensitive behavior in an interview mode experiment, São Paulo, Brazil, International Family Planning Perspectives, 2008, 34(4):169-176.

9. Potdar R and Koenig MA, Does audio-CASI improve reports of risky behavior? Evidence from a randomized field trial among young urban men in India, Studies in Family Planning, 2005, 36(2):107-116.

10. Le LC et al., A pilot of audio computer-assisted self-interview for youth reproductive health research in Vietnam, Journal of Adolescent Health, 2006, 38(6):740-747.

11. Langhaug LF, Sherr L and Cowan FM, How to improve the validity of sexual behaviour reporting: systematic review of questionnaire delivery modes in developing countries, Tropical Medicine $\varepsilon$ International Health, 2010, 15(3):362-381.

12. Gregson $\mathrm{S}$ et al., Methods to reduce social desirability bias in sex surveys in low-development settings: experience in Zimbabwe Sexually Transmitted Diseases, 2002, 29(10):568-575

13. Kaler A, "My girlfriends could fill a yanu-yanu bus": rura Malawian men's claims about their own serostatus, Demographic Research, 2003, Spec. Coll. 1, Art. 11, pp. 349-372, <http://www. demographic-research.org/special/1/11/sl-1l.pdf>, accessed Mar. 1,2012

14. Poulin M, Reporting on first sexual experience: the importance of interviewer-respondent interaction, Demographic Research, 2010 22(11):237-288, <http://www.demographic-research.org/volumes/ vol22/11/22-11.pdf>, accessed Dec. 15, 2011.

15. Glynn JR et al., Assessing the validity of sexual behaviour reports in a whole population survey in rural Malawi, PLoS ONE, 2011, 6(7):e22840, doi:10.1371/journal.pone.0022840, accessed Nov. 29, 2011.

16. Nnko S et al., Secretive females or swaggering males? An assessment of the quality of sexual partnership reporting in rural Tanzania Social Science \& Medicine, 2004, 59(2):299-310.

17. Curtis SL and Sutherland EG, Measuring sexual behaviour in the era of HIV/AIDS: the experience of Demographic and Health Surveys and similar enquiries, Sexually Transmitted Infections, 2004, 80(Suppl. 2):ii22-ii27.

18. Wellings $\mathrm{K}$ et al., Sexual behaviour in context: a global perspective, Lancet, 2006, 368(9548):1706-1728.

19. Luke N, Clark S and Zulu EM, The relationship history calendar: improving the scope and quality of data on youth sexual behavior, Demography, 2011, 48(3):1151-1176.

20. Mensch BS, Hewett PC and Erulkar AS, The reporting of sensitive behavior by adolescents: a methodological experiment in Kenya Demography, 2003, 40(2):247-268.

21. Glynn JR et al., Age at menarche, schooling, and sexual debu in northern Malawi, PLoS ONE, 2010, 5(12):e15334, doi:10.1371/ journal.pone.0015334, accessed Dec. 16, 2011

22. Clark S, Poulin M and Kohler HP, Marital aspirations, sexual behaviors, and HIV/AIDS in rural Malawi, Journal of Marriage and the Family, 2009, 71(2):396-416

23. Boerma JT et al., Understanding the uneven spread of HIV with in Africa: comparative study of biologic, behavioral, and contextual factors in rural populations in Tanzania and Zimbabwe, Sexually Transmitted Diseases, 2003, 30(10):779-787

24. Buvé A et al., Interpreting sexual behaviour data: validity issues in the multicentre study on factors determining the differential spread of HIV in four African cities, AIDS, 2001, 15(Suppl. 4):S117-S126.

25. Cantor D, A review and summary of studies on panel conditioning, in: Menard S, ed., Handbook of Longitudinal Research: Design, Measurement, and Analysis, London: Academic Press, 2008, pp. 123-138. 
26. Hewett PC et al., Using sexually transmitted infection biomarkers to validate reporting of sexual behavior within a randomized, experimental evaluation of interviewing methods, American Journal of Epidemiology, 2008, 168(2):202-211.

27. Minnis AM et al., Biomarker validation of reports of recent sexual activity: results of a randomized controlled study in Zimbabwe, American Journal of Epidemiology, 2009, 170(7):918-924.

28. Siegfried N and Mathews C, Commentary: All is not what it seems: a systematic review and meta-analysis of quantitative interviewing tools to investigate self-reported HIV and STI-associated behaviours in low- and middle-income countries, International Journal of Epidemiology, 2010, 39(6):1556-1557.

\section{RESUMEN}

Contexto: El sesgo de deseabilidad social (lo que se considera como socialmente deseable) es problemático para los estudios que dependen de datos autoreportados sobre la conducta sexual. Cuando las normas de género establecen expectativas diferentes acerca del comportamiento socialmente aceptable para hombres y mujeres, estos se enfrentan a presiones diferentes a la hora de informar sobre ciertos resultados, lo que puede distorsionar la valoración de riesgos relacionados con el VIH y las ITS.

Métodos: En 2009, y durante la tercera ronda del Estudio de Escolaridad y Adolescencia en Malaui, se recolectaron datos sobre relaciones y conducta sexual entre 1.750 hombres $y$ mujeres de edades comprendidas entre los 16 y los 18 años que no se habian casado. Los datos se recolectaron por medio de auto-entrevistas asistidas por computadora (audio-CASI). Un grupo de comparación compuesto por 311 jóvenes completó un cuestionario idéntico en entrevistas cara a cara. Para analizar si el tipo de entrevista pudo haber influido en los datos aportados por las personas participantes sobre conductas sensibles, se compararon los informes sobre experiencias sexuales de los dos grupos. Por medio del análisis de regresión logistica múltiple, se identificaron las asociaciones entre el modo de entrevista y los informes sobre estas conductas, agrupados por género. Resultados: Según los modelos de regresión ajustados, los hombres mostraron una probabilidad menor de informar sobre una compañera sentimental en audio-CASI que en las entrevistas personales (cociente de probabilidades, 0,4), y una probabilidad mayor de informar sobre relaciones sexuales con un familiar o maestro $(3,5)$. Para las mujeres, los informes sobre compañeros sentimentales o relaciones sexuales no difrieron según los modos de entrevista. Una pequeña proporción de mujeres reportó haber tenido alguna vez relaciones sexuales con un familiar o maestro en audio-CASI, pero ninguna lo hizo en las entrevistas personales.

Conclusiones: El método usado para obtener datos sobre relaciones y conducta sexual puede influir en la prevalencia reportada para algunas conductas clave, en particular entre hombres. Se necesita investigación adicional para mejorar los métodos para la recolección de datos sensibles.

\section{RÉSUMÉ}

Contexte: Le biais de désirabilité sociale pose problème dans les études basées sur des données de comportement sexuel autodéclarées. Là où les normes de genre créent différentes attentes concernant les comportements socialement acceptables, les hommes et les femmes subissent différentes pressions concernant la déclaration de certains résultats, donnant lieu à une distorsion possible des évaluations du risque de VIH et d'IST.

Méthodes: En 2009, des données de relation et de comportement sexuel ont été collectées auprès de 1.750 jeunes hommes et femmes célibataires jamais mariés de 16 à 18 ans par autoentretien audio assisté par ordinateur (audio-CASI), durant le troisième round de l'étude sur la scolarisation et les adolescents au Malawi (Malawi Schooling and Adolescent Study). Un groupe témoin de 311 jeunes a été soumis à un questionnaire identique dans le cadre d'entretiens en tête à tête. Pour évaluer l'influence éventuellement exercée suivant le mode d'entretien sur la déclaration de comportements sensibles, les déclarations d'expérience sexuelle ont été comparées entre les deux groupes. Les associations entre le mode d'entretien et les déclarations de ces comportements ont été identifiées, par sexe, par analyse de régression logistique multiple.

Résultats: Dans les modèles de régression corrigés, les jeunes hommes se révèlent moins susceptibles de déclarer avoir jamais eu une petite amie dans les entretiens audio-CASI que dans ceux en tête à tête $(O R, 0,4)$, mais plus susceptibles de déclarer avoir eu des rapports sexuels avec une parente ou une enseignante (3,5). Côté féminin, les déclarations d'avoir eu un petit ami ou d'avoir eu des rapports sexuels ne diffèrent pas suivant le mode d'entretien. Une faible proportion des filles déclare avoir eu des rapports sexuels avec un parent ou un enseignant dans les entretiens audio-CASI, par rapport à aucune dans les entrevues en tête à tête.

Conclusions: La méthode de collecte de données sur les relations et les comportements sexuels peut influencer la prévalence déclarée de certains comportements clés, en particulier chez les hommes. Une recherche approfondie est nécessaire à l'amélioration des méthodes de collecte de données sensibles.

\section{Acknowledgments}

This research was supported by grant R01-HD047764 from the Eunice K. Shriver National Institute of Child Health and Human Development and by The William and Flora Hewlett Foundation. The authors thank Patrick Makhuva, Baxter Nyirenda, and all the interviewers and supervisors in Malawi for their assistance with data collection. They also thank Joseph Chimombo for his guidance and Barbara Miller for her contributions to this project. The opinions expressed herein are those of the authors and do not necessarily reflect the views of the funding institutions.

Author contact: ckelly@popcouncil.org 